\title{
Beneficial effects of olive oil phenols on the aging process: Experimental evidence and possible mechanisms of action
}

\author{
Lisa Giovannelli \\ Department of Preclinical and Clinical Pharmacology, University of Florence, Viale G. Pieraccini 6, \\ 50139 Florence, Italy \\ Tel.: +39055 4271 322; Fax: +39055 4271 280; E-mail: lisa.giovannelli@unifi.it
}

Received 31 October 2012

Accepted 29 January 2013

\begin{abstract}
Human studies indicate that consumption of olive oil is associated with decreased mortality, reduced cardiovascular risk and improved cognitive function in the elderly. Many of these benefits are thought to be due to the phenolic content of olive oil. In support of this, intervention studies in humans indicate that olive oil phenols protect blood lipids from oxidation and improve blood parameters of inflammation, hemostasis and vascular function, all risk factors for cardiovascular disease. The aim of this review is to evaluate the experimental evidence that olive oil phenols are beneficial to the aging process. Animal studies suggest that olive oil phenols have preventive actions on age-related cognitive and motor dysfunction, an important cause of disability in the elderly. Supporting mechanistic in vitro studies indicate that olive oil phenols may inhibit inflammatory pathways and associated proteins, induce pathways related to cell protection and survival, and modulate pathways related to energy metabolism similar to anti-aging substances. Furthermore, they can interact with beta-amyloid peptide and Tau protein to inhibit the formation of protein aggregates, a hallmark of Alzheimer's disease. However, caution should be expressed in interpreting these in vitro data are as they are based on experiments carried out mainly using un-physiological concentrations of native olive phenols rather than phenolic metabolites. In conclusion, while in vivo data for the beneficial effects of olive oil phenols in aging are growing, a mechanistic explanation for these effects requires much additional research on the effects of metabolites at relevant concentrations.
\end{abstract}

Keywords: Olive phenols, oxidative stress, inflammation, behavior, cell survival, energy metabolism

\section{Abbreviations:}

$\mathrm{A} \beta=$ beta-amyloid peptide

AMPK = adenosine monophosphante-activated kinase

AP-1 = activator protein-1

$\mathrm{ARE}=$ antioxidant response element

COX = cyclooxygenase

$\mathrm{CREB}=\mathrm{cAMP}$ response element-binding protein

$\mathrm{CRP}=\mathrm{C}$-reactive protein

DSS $=$ dextran sulphate sodium

DPPH = diphenyl-2-picryl hydrazyl free radical
EMT $=$ epithelial-mesenchymal transition

ERK $=$ extracellular regulated protein kinase

EVOO = extra-virgin olive oil

$\mathrm{FOXO}=$ forkhead transcription factor

$\mathrm{GSH}=$ glutathione

$\mathrm{GR}=$ glutathione reductase

$\gamma$-GCL = gamma-glutamyl cysteine ligase

GPx $=$ glutathione peroxidase

GST $=$ glutathione S-transferase

$\mathrm{HDL}=$ high density lipoproteins

HO-1 = heme-oxygenase 1

HT $=$ hydroxytyrosol 


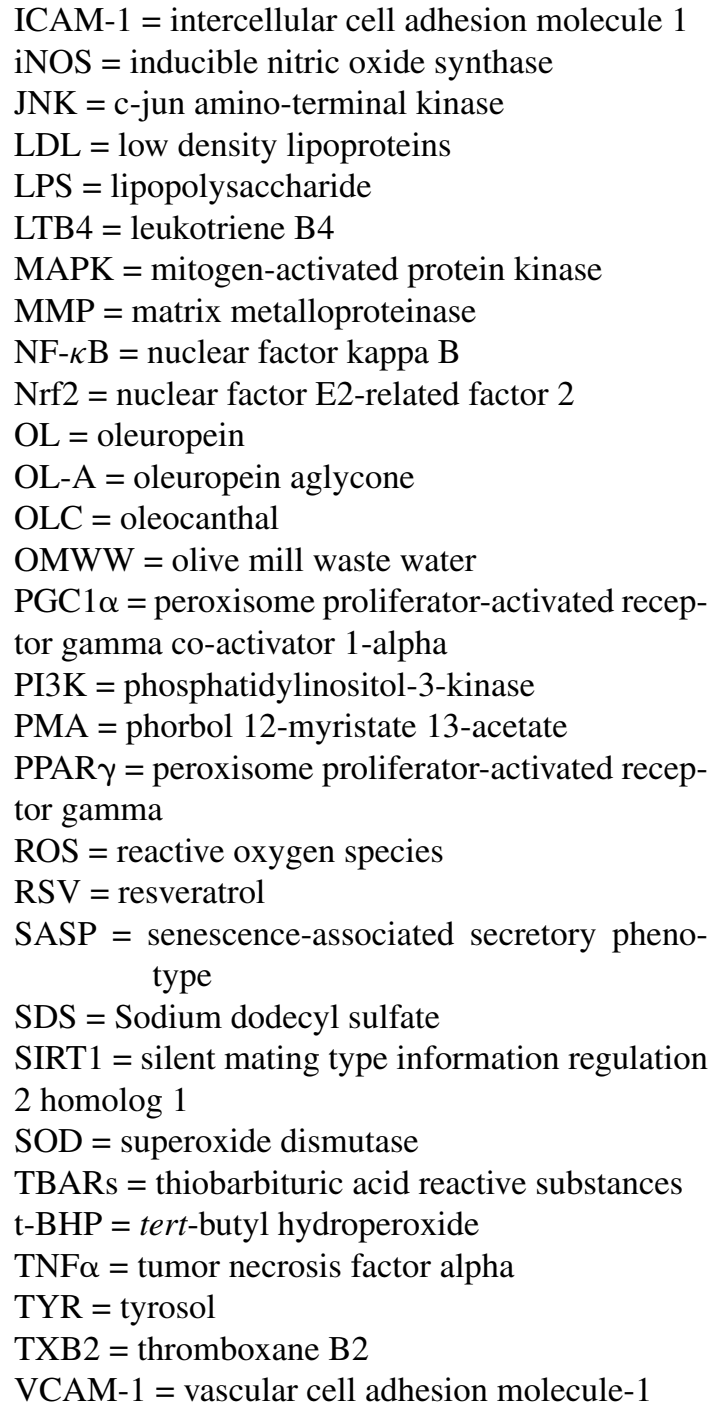

\section{Introduction}

Epidemiological studies indicate that the Mediterranean diet is associated with longevity and improved health during aging [1]. As olive oil is an important component of this diet, the association between olive oil consumption and "healthier aging" has been investigated. Indeed, olive oil intake has been negatively associated with cardiovascular risk in a large cohort of the European Prospective Investigation into Cancer and Nutrition (EPIC) study [2]. In the same group, olive oil intake was associated with decreased overall mortality [3]. Consumption of olive oil has also been seen to reduce levels of proinflammatory markers associated with atherosclerosis development in plasma and in blood cells $[4,5]$. Finally, the high intake of both total olive oil and virgin olive oil in older individuals with high cardiovascular risk has been associated with better memory function and global cognition as assessed by the Mini Mental State Examination (MMSE) and the Rey Auditory Verbal Learning Test (RAVLT) [6].

Some of the health benefits of olive oil are related to the fact that it is the richest source of the monounsaturated fatty acid oleic acid, but it is widely accepted that many of these benefits are due to its minor components in the non-saponifiable fraction (about $2 \%$ of total): phenolic compounds, phytosterols, tocopherols and pigments [7]. Among these, phenolic compounds have been studied extensively. The main phenolics present in olive oil are divided into three main classes, represented in differing proportions in olives, olive leaves, olive oil, olive cake (the main by-product of the oil extraction process) and olive mill waste water (OMWW): simple phenols (phenolic alcohols and acids partly deriving from the hydrolysis of secoiridoids, such as hydroxytyrosol and tyrosol), secoiridoids (oleuropein, ligstroside, their respective aglycone forms and their respective decarboxylated dialdehyde derivatives) and lignans [(1)-1-acetoxypinoresinol and pinoresinol] [8]. The glycosides are more abundant in leaves and olives, and are hydrolyzed by $\beta$-glycosidases during olive crushing to produce oil. In the olive waste waters, the simple phenols deriving from secoiridoid hydrolysis become prevalent [9].

The aim of this review is to evaluate the experimental evidence that olive oil phenols are beneficial to the aging process. To this aim, data describing the relative effects of olive oil with differing contents of phenolic compounds, or those using extracts of various origin (olive leaf, oil and its processing by-products) standardized for their phenolic content, or pure olive phenols will be discussed. Studies where the effects of phenols are not distinguishable from those of oleic acid or other components of the oil have not been considered.

The first part of this review deals with the data relating to age-related markers in human studies and to in vivo and in vitro studies in aging models. In the second part, studies aimed at evaluating the effects of olive oil phenols on cellular function and molecular pathways have been analyzed in light of their possible relevancy to the aging process. 


\section{Evidence of beneficial effects of olive oil phenols on aging}

\subsection{Human intervention trials}

Intervention studies with olive oils or preparations of phenolic mixtures from olive mill waste water or other olive sources have been performed in healthy volunteers, and in subjects with different degrees of cardiovascular risk. The doses of total phenols employed ranged from a few $\mathrm{mg} /$ day to about $30 \mathrm{mg} /$ day, depending on the type of olive oil [10, $11]$, and reached $100 \mathrm{mg} /$ day in trials using olive oil enriched with olive extracts $[12,13]$. The duration of the intervention studies has in most cases been around one month and most were aimed to evaluate antioxidant and anti-inflammatory effects in vasculature along with parameters of vascular function, notably LDL oxidation urinary isoprostanes, serum antioxidant capacity, endothelial-induced vaso-relaxation, blood pressure, serum lipid levels, blood clotting factors, and inflammatory mediators. These data have been repeatedly reviewed elsewhere [14-17] and will be briefly recapitulated here. The EUROLIVE multicenter study has shown in a large sample of healthy European subjects that olive oil phenols dose-dependently protect blood lipids from oxidation, increase HDL cholesterol and the reduced/oxidized GSH ratio, without changes in plasma antioxidant capacity and F2-isoprostanes [14]. The European Food Safety Authority has recently approved a claim that olive oil polyphenols protect LDL against oxidation at a minimal dose of $5 \mathrm{mg} / \mathrm{kg} /$ day hydroxytyrosol [18]. Studies have also reported reduced plasma levels of TXB2 and LTB4, ICAM-1, VCAM-1 and CRP, along with improved endothelial function [19], reduced expression of proatherogenic genes in blood cells [20] and decreased blood pressure [21]. Thus, there is evidence that olive oil phenols may help prevent cardiovascular disease in humans.

\subsection{Effects on aging: Laboratory animal studies}

Recent animal aging studies have used extra-virgin olive oils (EVOO) rich in phenolic compounds (either naturally or otherwise) compared to control oil with lower phenolic but identical micro- and macro-nutrient content. In a rat model of physiological aging olive oil phenols have been reported to counteract some of the detrimental effects of age when administered with a hypercaloric diet [22, 23]. Specifically, these studies show that the long-term intake of EVOO rich in phenolic compounds delayed mortality, reduced the incidence of ulcerative dermatitis, and decreased oxidative damage in blood, while also inducing a borderline protective effect on motor coordination, and reduced anxiety associated with decreased glutathione reductase activity and expression in the brain. A similar long-term intervention in mice with a lower intake of EVOO, mimicking the MUFA intake of the Mediterranean diet, indicated that olive oil phenols improved motor coordination and contextual memory after 6 months of treatment, along with a reduction of some oxidative stress and inflammation parameters in the brain, particularly in the cerebellum [24].

SAMP8 mice are a well-characterized model of accelerated senescence. These animals show high levels of oxidative damage in organs such as heart and brain, and $\beta$-amyloid deposition in the brain along with cognitive deficits. In SAMP8 mice treated with a diet rich in olive oil phenols (10\% EVOO) for 4.5 months, the levels of oxidative stress (TBARs and protein carbonyls) in the heart were reduced, and an induction of genes related to antioxidant defenses and longevity was demonstrated [25]. In the same animal model of accelerated aging, EVOO as such or enriched with an extracted phenolic fraction (total phenol doses ranging from $6 \mathrm{mg} / \mathrm{kg} /$ day in EVOO to $30 \mathrm{mg} / \mathrm{kg} /$ day in enriched EVOO, for 6 weeks), improved acquisition and retention in the T-maze test and memory retention in a one-trial novel object recognition test, as compared to mice receiving iso-caloric coconut oil or butter [26]. These functional changes were accompanied by increased GSH levels, enhanced glutathione reductase (GR) and SOD activity, and reduced lipid and protein oxidation.

Such effects may be mediated by the potential of olive oil phenols to pass the blood/brain barrier and reach the brain [27, 28], although the precise concentrations of phenolic compounds reaching the brain upon repeated administration, such as those used in the above studies, is unclear. However, ex vivo data on damage after hypoxia-re-oxygenation in brain slices indicate that neuroprotective concentrations can be reached [29]. In fact, these authors showed that the 3 -month treatment of diabetic rats with virgin olive oil $(0.125 \mathrm{mg} / \mathrm{kg}$ per day total phenols) displayed a stronger neuroprotective activity than aspirin $(2 \mathrm{mg} / \mathrm{kg}$ per day). An antioxidant effect of this treatment was 
also shown in healthy animals using the same experimental protocol [30].

These animal studies indicate that behavioral improvement of both motor and cognitive functions is attainable with dietary amounts of olive oil phenols upon long-term treatment, and point out concomitant changes in the brain and peripheral organs, mainly a reduction of oxidative stress and inflammation parameters, and increases in antioxidant/detoxification-related gene expression. However, none of these studies has provided a mechanistic explanation for the observed effects, and the biochemical changes essential to counteract age-related behavioral dysfunctions still need to be clarified.

In a rat model of senile osteoporosis (ovariectomy + magnesium silicate-induced granulomatosis) oleuropein (about $10 \mathrm{mg} / \mathrm{kg}$ ) and olive oil, both added to the diet for 80 days, were able to counteract bone loss and reduce $\alpha-1$-acid glycoprotein plasma concentrations [31]. In the same model, both hydroxytyrosol (HT) and tyrosol (TYR), at doses of about $6 \mathrm{mg} / \mathrm{kg}$, and an olive mill waste water extract containing mainly HT and TYR, added to the diet for about 3 months also counteracted bone loss [32]. Although phenols did not modify markers of inflammation such as plasma fibrinogen and spleen weight, a significant reduction in urinary isoprostanes was seen without changes in plasma antioxidant capacity. Other mechanisms besides antioxidant/anti-inflammatory action might be relevant in this context, including the possibility that olive oil phenols have estrogenic activity, although this remains to be confirmed. However, the fact that olive oil phenols did not protect from bone loss in ovariectomized animals without inflammation seems to indicate that any estrogenic effects were not important, at least under these experimental conditions. The peroxisome proliferator-activated receptor gamma (PPAR $\gamma$ ) has been shown to be involved in the enhanced osteoblastic differentiation induced in bone marrow stem cells by oleuropein $(1-100 \mu \mathrm{M})$ [33], offering another possible hypothesis on the mechanism of the preventive activity of oleuropein on osteoporosis.

One important point emerging from all the animal studies is that beneficial effects on aging are attainable at low doses, which are realistic in respect to olive oil intake in the Mediterranean diet, provided that the oil has a sufficiently high content of polyphenols. Furthermore, no toxicity was observed with such doses, even in the chronic studies. On the other hand, these studies do not provide many clues about the attribution of the observed effects to specific compounds, or to additive or synergistic interactions among the diverse compounds in the oils. Finally, the data obtained in animal models will have to be confirmed in humans.

\subsection{Effects on aging: In vitro studies}

Much work has been conducted in in vitro aging models to assess the activity of olive phenols. The progressive slowing and irreversible arrest of their proliferative capacity, along with an array of typical morphological, functional and biochemical changes, characterizes the aging of cells in culture. The anti-aging potential of any substance may be described if it modifies the total number of replications that proliferating cells can undergo before senescence, thus affecting the so-called "replicative senescence". Alternatively, an anti-aging compound may lengthen "chronological lifespan", i.e. the time cells can remain quiescent in culture before entering replicative arrest; in this case cells reach senescence without telomere attrition. In normal human fibroblasts, HT prolonged chronological lifespan at $1 \mu \mathrm{M}$ upon 30 days of continuous exposure [34]. Although these effects were suggested to be mediated by the concomitant induction of MnSOD, they were observed at non-physiological concentrations (10 and $200 \mu \mathrm{M}$ ), and cell transfection with a dominantnegative mutant of MnSOD did not completely abolish HT-induced extension of cell culture chronological lifespan. Thus, it is possible that other factors besides MnSOD activity regulate this effect of HT.

A 3-month treatment with Olea europaea leaf extract or purified oleuropein significantly delayed replicative senescence and the development of the senescent morphology in IMR90 and WI38 human embryonic fibroblasts. Shorter-term treatment with oleuropein also reduced oxidized proteins and ROS production in cultures, and improved cell viability upon treatment with different oxidants [35]. The antiaging effects of olive oil phenols have also been studied in a model of epithelial-mesenchymal transition (EMT), a critical step in age-related human diseases involving organ fibrosis. EMT is involved in kidney fibrosis in chronic renal disease, liver fibrosis in non-alcoholic steatohepatitis, in myocardial fibrosis in heart failure, and also in tumor-stem cell transition [36]. A phenol extract from olive oil (equivalent to about $0.37 \mu \mathrm{M}$ oleuropein, for 3 days), consisting mostly in secoiridoids, prevented EMT in both renal 
MDCK cells (a model of organ fibrosis) and in MCF7 breast cancer cells (a model of oncogenic EMT). It is interesting that other anti-aging molecules such as rapamycin and metformin have been shown to counteract EMT $[37,38]$. One cellular target that has been shown to be involved in EMT is AMPK (adenosine monophosphate kinase), and some data in the literature indicate that AMPK might indeed be modulated by olive oil phenols (see below).

In agreement with these data, pre-treatment for 1 month with $5 \mathrm{mg} / \mathrm{kg}$ TYR reduced post-infarct fibrosis in the rat heart compared with untreated controls [39]. Thus, EMT modulation might represent a novel mechanism through which EVOO phenols regulate the pathophysiology of some age-related human diseases.

\section{Pharmacokinetic considerations}

Pharmacokinetic studies in humans and laboratory animals have shown that HT and TYR are well absorbed in the gastrointestinal tract and extensively metabolized through conjugation and methylation, with peak plasma concentrations detected about $1-2 \mathrm{~h}$ post-consumption [40, 41]. Secoiridoid molecules such as oleuropein are poorly absorbed in the small intestine and can reach the large intestine where they are degraded by the microbiota to yield HT concentrations in the high $\mu \mathrm{M}$ range $[42,43]$, whereas the aglycones are absorbed and metabolized in the small intestine, mostly to reduced compounds which are then conjugated with glucuronic acid [44]. In plasma, different metabolites have been identified, at concentrations generally below the micromolar range $[41,45]$. In urine, the free forms are also present $[46,47]$. A recent study investigating the distribution of acutely administered phenols (extracted from olive cake) in rats, has shown that relevant amounts of metabolites can reach organs such as brain, heart, testicle, spleen and thymus, in addition to the liver and kidney where they are expected due to metabolism and excretion [28].

Furthermore, the type of metabolites and their concentrations differ from one tissue to another. In plasma, phenolic alcohols and acids are the most abundant species (respectively about $70 \%$ and $20 \%$ of total at $2 \mathrm{~h}$ ), as a result of secoiridoid hydrolysis taking place in the gastrointestinal tract. The prevalent metabolites were sulfates of HT, TYR and homovanillic acid, whereas the glucuronides were present at much lower concentrations. Unconjugated compounds were also detected, although in low concentrations, and possibly only due to the high dose of extract administered (corresponding to $300 \mathrm{mg} / \mathrm{kg}$ total phenols, about 50 times higher than the doses used in the in vivo experiments in aging animals) due to the saturation of intestine/liver conjugation capacity. Free HT was not recovered in liver and brain, but was detectable in kidney and testicle. Interestingly, HT-sulfate $(89 \mathrm{nM}$ in plasma after $2 \mathrm{~h}$ ) was detected in the brain, spleen, heart and testicles at concentrations of 50, 12, 263 and $1005 \mathrm{nmol} / \mathrm{g}$ tissue respectively, indicating that some tissues can concentrate phenolic metabolites. Furthermore, it is feasible that higher amounts can be reached upon repeated administrations, such as those employed in most of the in vivo studies outlined in the aging studies. However, this point has not yet been demonstrated.

The in vitro studies pose more problems with respect to kinetics: firstly the concentrations employed in cell models are in some cases too high to be relevant in vivo. Secondly, in most cases the original compounds have been used, without taking into account metabolism. Based on what we know thus far regarding the kinetics of these compounds, cells are exposed predominantly to low concentrations of metabolites in vivo, with the exception of those in the gastrointestinal tract mucosa, which are more likely to be exposed to higher concentrations of unmodified compounds. Actual studies regarding the biological effects of metabolites are scarce and results are conflicting. Synthesized HT glucuronide metabolites do not display significant chemical and biological antioxidant activities in vitro (scavenging activity and $\mathrm{Cu}$-mediated LDL oxidation) at concentrations measured in vivo in humans (0.01-10 $\mathrm{M})$ [48], whereas the urinary-isolated 3O-glucuronide conjugate shows higher antioxidant potency than HT in the in vitro DPPH Scavenging Test [49]. Thus, confirmation of the effects upon exposure to relevant concentrations of the various metabolites is urgently needed.

\section{Cellular and molecular mechanisms of action}

The possible mechanisms underlying the effects of olive phenols against aging are varied and thus have been divided into four groups according to their function: 
Table 1

Summary of studies on the molecular mechanisms of action of olive oil phenolic compounds

\begin{tabular}{|c|c|c|c|}
\hline Olive phenolic compound or mixture & Experimental model & Olive phenol-induced molecular changes & Ref. number \\
\hline \multicolumn{4}{|l|}{ Inflammatory pathways and enzymes } \\
\hline HT, TYR & Neuroblastoma N2a cells exposed to $A \beta$ & Reduced nuclear NF- $\kappa$ B translocation & {$[56]$} \\
\hline $\begin{array}{l}\text { Olive oil extract }(0.25-7.5 \mu \mathrm{g} / \mathrm{mL}) \\
\text { containing mainly secoiridoids; HT, } \\
\text { TYR, OL-A }(0.5-25 \mu \mathrm{M})\end{array}$ & $\begin{array}{l}\text { Human gastric adenocarcinoma cells } \\
\text { (AGS) }\end{array}$ & Reduced NF- $\kappa$ B-induced transcription & {$[57]$} \\
\hline HT, OL-A $(5-75 \mu \mathrm{M})$ & $\begin{array}{l}\text { Vascular endothelial cells (HUVECs) } \\
\text { exposed to LPS, TNF } \alpha \text {, PMA }\end{array}$ & Inhibition of VCAM-1 expression & {$[58]$} \\
\hline HT, RSV (1 $\mu \mathrm{M})$ & $\begin{array}{l}\text { Vascular endothelial cells (HUVECs) } \\
\text { exposed to homocysteine }\end{array}$ & $\begin{array}{l}\text { Inhibition of VCAM-1 expression; reduced } \\
\text { monocytoid cell adhesion to } \\
\text { endothelium }\end{array}$ & {$[59]$} \\
\hline $\begin{array}{l}\text { Olive pomace extract rich in TYR and } \\
\text { OL, purified TYR }(72 \mu \mathrm{M}) \text { and OL } \\
(92 \mu \mathrm{M})\end{array}$ & $\begin{array}{l}\text { Vascular endothelial cells (EAhy926) } \\
\text { exposed to anoxia }\end{array}$ & $\begin{array}{l}\text { Reduced nuclear NF- } \kappa \text { B translocation and } \\
\text { expression of iNOS, COX-2, MMP-2 } \\
\text { and MMP-9; MAPK and ERK } \\
\text { 1/2activation }\end{array}$ & {$[60]$} \\
\hline $\begin{array}{l}\text { Olive oil extract rich in OL-A, OL-A } \\
5-50 \mu \mathrm{M})\end{array}$ & $\begin{array}{l}\text { Human monocytic leukemia cells } \\
\text { (THP-1) stimulated with TNF } \alpha\end{array}$ & $\begin{array}{l}\text { Inhibition of NF- } \kappa \text { B-mediated gene } \\
\text { expression; reduced MMP-9 secretion }\end{array}$ & {$[61]$} \\
\hline $\begin{array}{l}\text { EVOO extract (total phenols } \\
\qquad 1 \mathrm{nM}-10 \mu \mathrm{M})\end{array}$ & $\begin{array}{l}\text { Isolated human monocytes and } \\
\text { monocyte-derived macrophages } \\
\text { treated with PMA }\end{array}$ & Reduced nuclear NF- $\kappa \mathrm{B}$ translocation & {$[62]$} \\
\hline $\begin{array}{l}\text { Olive leaf extract (dose equivalent to } \\
22 \mathrm{mg} / \mathrm{kg} \mathrm{HT} \text { ) }\end{array}$ & $\begin{array}{l}\text { Rabbit model of high lipid-induced } \\
\text { atherosclerosis }\end{array}$ & $\begin{array}{l}\text { Reduced expression of MCP-1, VCAM-1, } \\
\text { NF- } \kappa \mathrm{B} \text { and } \mathrm{TNF} \alpha\end{array}$ & {$[63]$} \\
\hline $\begin{array}{l}\mathrm{OLC}\left(\mathrm{IC}_{50}=25 \mu \mathrm{M}\right), \mathrm{HT}\left(\mathrm{IC}_{50}=3-10\right) \\
\text { peracetylated } \mathrm{HT} \text { derivative } \\
\left(\mathrm{IC}_{50}=0.1-1 \mu \mathrm{M}\right) \text { respectively for } \\
\text { COX-1 and } 2\end{array}$ & In vitro phenol-protein interaction & Inhibition of COX-1 and 2 & {$[64,65]$} \\
\hline $\begin{array}{l}\text { EVOO or EVOO enriched with HT (final } \\
\text { HT dose } 5 \mathrm{mg} / \mathrm{kg} \text { ) }\end{array}$ & DSS-induced cholitis in mice & $\begin{array}{l}\text { Inhibited phosphorylation of p38 MAPK } \\
\text { and down-regulation of COX-2 and } \\
\text { iNOS in colon mucosa }\end{array}$ & {$[68]$} \\
\hline $\begin{array}{l}\text { EVOO-derived extract (phenolic } \\
\text { concentrations in the high } \mu \mathrm{M} \text { range) }\end{array}$ & $\begin{array}{l}\text { Human colon adenocarcinoma }(\mathrm{CaCo}-2) \\
\text { cells }\end{array}$ & $\begin{array}{l}\text { Inhibited MAPK pathway and COX-2 } \\
\text { expression }\end{array}$ & {$[69]$} \\
\hline $\begin{array}{l}\text { EVOO extract (secoiridoid } \\
\text { concentrations around } 20 \mu \mathrm{M} \text { ) }\end{array}$ & Breast cancer cells (JIMT-1) & Increased MAPK activation & {$[70]$} \\
\hline \multicolumn{4}{|c|}{ Pathways related to cell protection and survival } \\
\hline HT $(50 \mu \mathrm{M})$ & Porcine vascular endothelial cells & $\begin{array}{l}\text { Akt and ERK1/2 activation; increased Nrf2 } \\
\text { expression and nuclear translocation and } \\
\text { HO-1 induction; increased MAPK } \\
\text { phosphorylation }\end{array}$ & [71] \\
\hline $\mathrm{HT}(0.5-10 \mu \mathrm{M})$ & HepG2 hepatoma cells & $\begin{array}{l}\text { Induction of Nrf } 2 \text { nuclear translocation and } \\
\text { of GPx, GR, GST expression; increased } \\
\text { phosphorylation of Akt and ERK }\end{array}$ & [76] \\
\hline HT (100-200 $\mu \mathrm{M})$ & $\begin{array}{l}\text { Retinal pigment epithelial cells } \\
\text { (ARPE-19): basal or exposed to } \\
\text { acrolein or t-BHP }\end{array}$ & $\begin{array}{l}\text { Increased Nrf2 expression and nuclear } \\
\text { translocation; GPx, GR, } \gamma-\mathrm{GCL} \\
\text { expression and HO-1 induction; } \\
\text { increased AMPK phosphorylation; } \\
\text { increased PGC1 } \alpha \text { and mitochondrial } \\
\text { protein expression }\end{array}$ & {$[77-79]$} \\
\hline Phenol-rich EVOO (10\% w/w diet) & SAMP8 mice & $\begin{array}{l}\text { Induction of Nrf2, Nrf2-dependent gene } \\
\text { expression and of SIRT-1 in the heart }\end{array}$ & {$[25]$} \\
\hline HT $(25-100 \mu \mathrm{M})$ & NIH 3 T3 murine fibroblasts & $\begin{array}{l}\text { Nrf2-dependent trans-activation Increased } \\
\text { Nrf2 expression }\end{array}$ & \\
\hline TYR (5 mg/kg) & Rat model of myocardial infarction & $\begin{array}{l}\text { Increased Akt and FOXO3a } \\
\text { phosphorylation; increased SIRT1 } \\
\text { expression in the heart }\end{array}$ & [39] \\
\hline Olive leaf extract, OL $(0.2-90 \mu \mathrm{M})$ & $\begin{array}{l}\text { Human embryonic fibroblasts (IMR90 } \\
\text { and WI38) }\end{array}$ & Increased proteasomal enzymatic activities & {$[35]$} \\
\hline
\end{tabular}


Table 1

(continued)

\begin{tabular}{|c|c|c|c|}
\hline $\begin{array}{l}\text { Olive phenolic compound or } \\
\text { mixture }\end{array}$ & Experimental model & Olive phenol-induced molecular changes & Ref. number \\
\hline \multicolumn{4}{|c|}{ Pathways related to energy metabolism } \\
\hline $\mathrm{HT}(50 \mu \mathrm{M})$ & Porcine vascular endothelial cells & $\begin{array}{l}\text { Increased AMPK phosphorylation; } \\
\text { increased FOXO3a expression }\end{array}$ & [91] \\
\hline HT $(0.1-10 \mu \mathrm{M})$ & 3T3-L1 adipocytes & $\begin{array}{l}\text { Increased AMPK phosphorylation; } \\
\text { increased PGC } 1 \alpha \text { and Complex I protein } \\
\text { level; increased activity of Complexes } \\
\text { I-V }\end{array}$ & [92] \\
\hline OLC $(0.2-10 \mu \mathrm{M})$ & HT-29 cells & $\begin{array}{l}\text { Increased AMPK phosphorylation; } \\
\text { reduced COX-2 expression }\end{array}$ & [93] \\
\hline HT $25 \mathrm{mg} / \mathrm{kg} /$ day & $\begin{array}{l}\text { Rats subjected to excessive physical } \\
\text { exercise }\end{array}$ & $\begin{array}{l}\text { Increased mitochondrial Complex I and II } \\
\text { activities; prevented the fall of PGC1 } \alpha \text { in } \\
\text { muscle; increased autophagy in muscle. }\end{array}$ & [100] \\
\hline \multicolumn{4}{|c|}{ Interaction with $\beta$-amyloid peptide and Tau protein } \\
\hline OLC $(1-10 \mu \mathrm{M})$ & Primary hippocampal neuronal cultures & $\begin{array}{l}\text { Inhibition of } A \beta \text { oligomers toxicity } \\
\text { through direct interaction }\end{array}$ & [101] \\
\hline OLC ( $\mathrm{IC}_{50}$ about $\left.3 \mu \mathrm{M}\right)$ & In vitro phenol-protein interaction & Inhibition of Tau fibrillization & {$[102,103]$} \\
\hline OL & In vitro phenol-protein interaction & Interaction with $\mathrm{A} \beta$ peptides & {$[104,105]$} \\
\hline OL-A & & $\begin{array}{l}\text { Disruption of } A \beta \text { aggregation and } \\
\text { reduction of cytotoxicity }\end{array}$ & [106] \\
\hline OL $(12.5-50 \mu \mathrm{M})$ & $\begin{array}{l}\text { Human embryonic kidney cells } \\
\text { (HEK293), human neuroblastoma cells } \\
\text { (SK-N-SH) }\end{array}$ & $\begin{array}{l}\text { Increased APP } \alpha \text {-secretase cleavage with } \\
\text { reduced formation of } A \beta \text { oligomers }\end{array}$ & [107] \\
\hline
\end{tabular}

1. Inflammatory pathways and enzymes

2. Pathways related to cell protection and survival

3. Pathways related to energy metabolism

4. Interaction with $\beta$-amyloid peptide and Tau protein.

A summary of studies on the molecular mechanisms of action of olive oil phenolic compounds is shown in Table 1.

\subsection{Inflammatory pathways and enzymes}

Chronic inflammation occurs more commonly with advanced age, and inflammation is tightly entangled with the aging process [50]. The search for new anti-inflammatory drugs with minimal adverse effects, particularly following prolonged use, or nutraceuticals with anti-inflammatory properties for the treatment of chronic inflammatory pathologies common in aging, such as osteoarthritis and neuroinflammation, is gaining in interest [51].

\subsection{1. $N F-\kappa B / A P-1$}

The activation of Nuclear Factor $\kappa \mathrm{B}$ (Fig. 1) in cultured, aged cells precedes the expression of the socalled "senescence-associated secretory phenotype"
(SASP), i.e. the production and release of a number of inflammatory cytokines, extracellular proteases and growth factors. The SASP is thought to contribute to create a low level-inflammation state in aged tissue, and a tumor-favoring microenvironment [52]. Increased $\mathrm{NF}-\kappa \mathrm{B}$ activation has been found in senescent cultured endothelial cells [53] but its inhibition delays agerelated symptoms and pathologies in progeroid mice, reduces oxidative DNA damage and stress, and delays cellular senescence [54]. The administration of blueberry decreases NF- $\kappa$ B levels in the brain of aging rats and improved memory in object recognition tests [55].

As observed with many polyphenols, olive oil phenols have been shown to inhibit NF- $\kappa$ B activation under various experimental conditions. For example, the nuclear translocation of the NF- $\kappa \mathrm{B}$ subunits after $A \beta$ exposure of neuroblastoma cells was attenuated in the presence of TYR or HT [56]. Furthermore, NF-kBinduced transcription was inhibited by an olive extract containing mainly secoiridoids and by single compounds in human gastric adenocarcinoma cells [57].

In the vasculature, $\mathrm{NF}-\kappa \mathrm{B}$ activation is associated with a cascade of events leading to endothelial damage, monocyte adhesion to the endothelium and, in the long run, to atherogenesis. In cultured endothelial cells, HT and oleuropein showed a strong 
anti-inflammatory activity inhibiting VCAM-1 mRNA expression induced by LPS, TNF $\alpha$ and PMA [58]. The effect was dependent on the presence of the binding sites for NF- $\kappa$ B and AP-1 in the VCAM-1 promoter region, and both transcription factors were significantly inhibited by HT and oleuropein. This work showed that oleuropein was more potent than HT and resveratrol in reducing endothelial activation, and pointed out that all these compounds probably act downstream of surface receptors, modulating intracellular signaling cascades. The same group has shown that resveratrol and HT, but not folate and vitamin B6, strongly reduce homocysteine-induced VCAM1 expression in endothelial cells and monocytoid cell adhesion to the endothelium [59].

Similarly, an olive pomace extract rich in TYR and oleuropein was able to inhibit NF- $\kappa \mathrm{B}$ in endothelial cells subjected to anoxia, together with the expression of pro-inflammatory enzymes transcriptionally controlled by NF- $\kappa \mathrm{B}$, such as iNOS, COX-2, MMP9 [60]. Furthermore, an olive oil phenolic extract, rich in oleuropein aglycone, was found to inhibit $\mathrm{NF}-\kappa \mathrm{B}$-mediated gene expression in human monocytes stimulated with $\mathrm{TNF} \alpha$ [61] and this effect was only partially reproduced by oleuropein aglycone. In freshly isolated human monocyte/macrophage cells, an extra-virgin olive oil extract was effective in inhibiting PMA-induced NF- $\kappa \mathrm{B}$ translocation in the nucleus [62]. Lastly, an olive leaf extract was found to down-regulate the expression of MCP-1, VCAM- $1, \mathrm{NF}-\kappa \mathrm{B}$ and TNF $\alpha$ at both protein and mRNA level in a rabbit model of high lipid-induced atherosclerosis [63].

\subsubsection{COX inhibition}

Oleocanthal, the dialdehydic form of decarboxymethyl ligstroside aglycone (p-HPEA-EDA, OLC) has been found to display ibuprofen-like properties, inhibiting both COX-1 and 2 in vitro [64]. However, the IC50 is about $25 \mu \mathrm{M}$ for both enzymes, so it is questionable if these effects are of systemic importance following the consumption of olive oil or other olive tree products. In addition, HT was shown to inhibit COX-1 and 2 in vitro, and its peracetylated semisynthetic derivative was more potent than OLC [65].

\subsection{3. p38MAPK signaling pathway}

Mammalian p38 mitogen-activated protein kinase (p38MAPK) is the signaling target of a wide variety of cellular stresses, including oxidative stress and inflammatory signals (Fig. 1), and is an important regulator

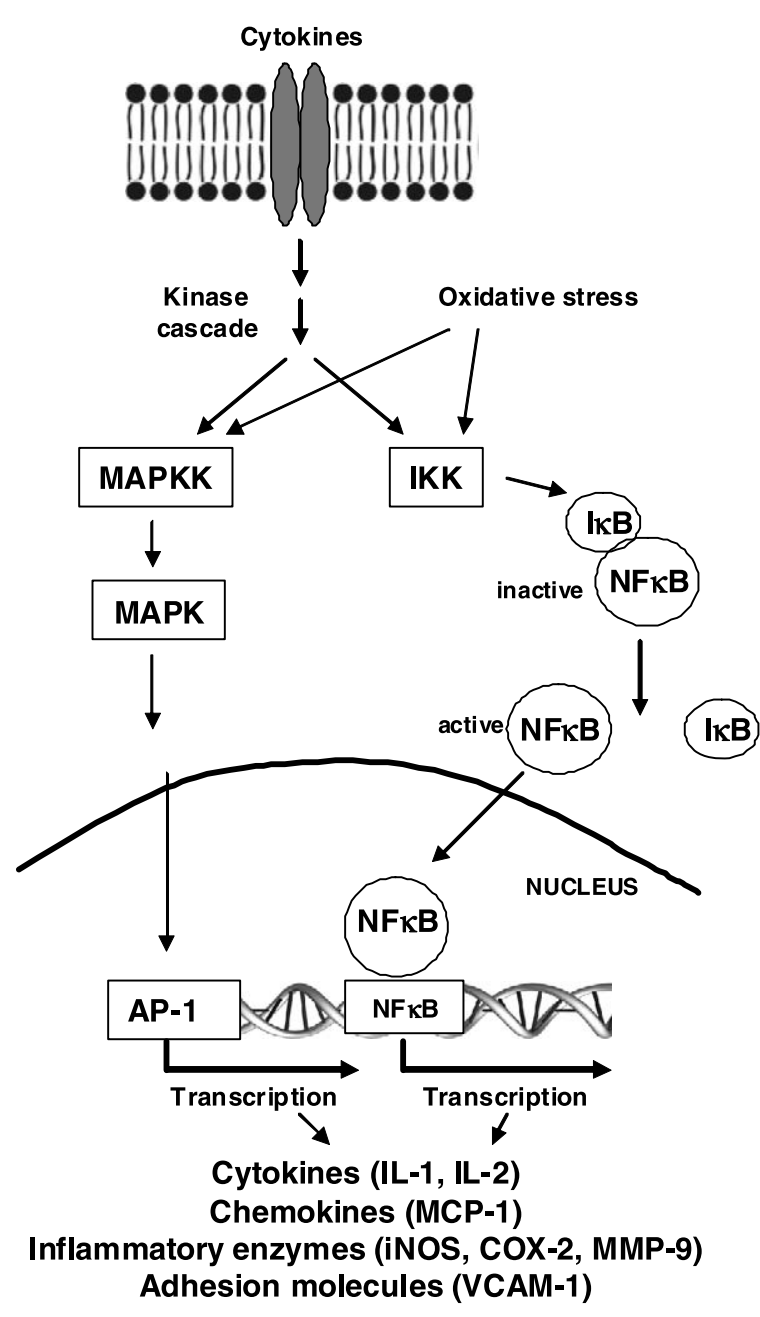

Fig. 1. Schematic representation of pathways involved in inflammatory signaling: MAPK and $\mathrm{NF} \kappa \mathrm{B}$ pathways.

of the inflammatory process [66]. Senescence induction in vitro is associated with MAPK induction, and MAPK inhibition reduces the secretion of SASP factors in senescent cells [67]. In DSS-induced cholitis, a mouse model of chronic inflammation, the phosphorylation of p38MAPK was inhibited in mouse colon mucosa upon treatment with EVOO or EVOO enriched with HT [68]. Inhibition of this pathway was also reported in human colon adenocarcinoma (CaCo2) cells exposed to an EVOO-derived polyphenolic extract, concomitantly with reduced proliferation, CREB phosphorylation and COX-2 expression [69].

Other studies report instead activation of MAPK upon treatment with olive phenols. For example, in breast cancer cells the anti-proliferative effects of 
phenolic mixtures extracted from extra-virgin olive oil were associated with MAPK activation [70]. Increased MAPK phosphorylation was also reported in vascular endothelial cells treated with $50 \mu \mathrm{M} \mathrm{HT}$, although MAPK was not involved in HT-mediated cell protection against $\mathrm{H}_{2} \mathrm{O}_{2}$ [71]. Furthermore, an olive pomace containing mainly oleuropein and TYR has been shown to activate p38MAPK in endothelial cells subjected to anoxia, but the two main phenols were only partly responsible for the observed effects of pomace in these cells [60]. Indeed, a non-phenolic component of olive oil, the triterpenoid oleanolic acid, has been shown to rapidly induce p38MAPK in human coronary smooth muscle cells and this induction appears to be essential for the up-regulation of COX-2 and consequent prostaglandin release induced by oleanolic acid [72].

On the whole, these data do not provide univocal conclusions on the effects of olive oil phenols on MAPK pathway, as specific effects might depend on cell type, on cell phosphorylation status, and/or on the presence and activity of other minor components in olive extracts.

\subsection{Pathways related to cell protection and survival}

Among the many factors involved in the temporal development and quality of aging, the accumulation of cellular and molecular damage is one of the most studied. Oxidative damage, along with impaired mitochondrial electron transport [73], and impaired protein turnover lead to progressive cellular dysfunction and death, and are considered possible targets for preventive and therapeutic strategies. It has been questioned whether natural polyphenols can exert direct scavenging effects in vivo, mainly due to the low concentrations achieved in blood compared to the active concentrations in vitro [74]. Recently, the prevalent interest is in evaluating indirect pathways, such as the modulation of the expression of antioxidant and detoxifying enzymes.

\subsubsection{Nrf2 pathway}

Several reports indicate that olive oil phenols are able to activate the nuclear factor E2-related factor 2 (Nrf2) pathway, similarly to other antioxidant compounds [75], promoting its nuclear translocation (Fig. 2) and, in some cases, increasing its expression. Induction of the Nrf2-dependent antioxidant/detoxifying enzymes glutathione peroxidase (GPx), glutathione reductase (GR) and glutathione S-transferase (GST), along with Nrf2 nuclear translocation has been reported in vitro in HepG2 hepatoma cells exposed to HT [76]. In vascular endothelial cultured cells, silencing experiments have shown that Nrf2 was essential for both the cytoprotective activity of HT towards $\mathrm{H}_{2} \mathrm{O}_{2}$ and the increased endothelial prolifer-

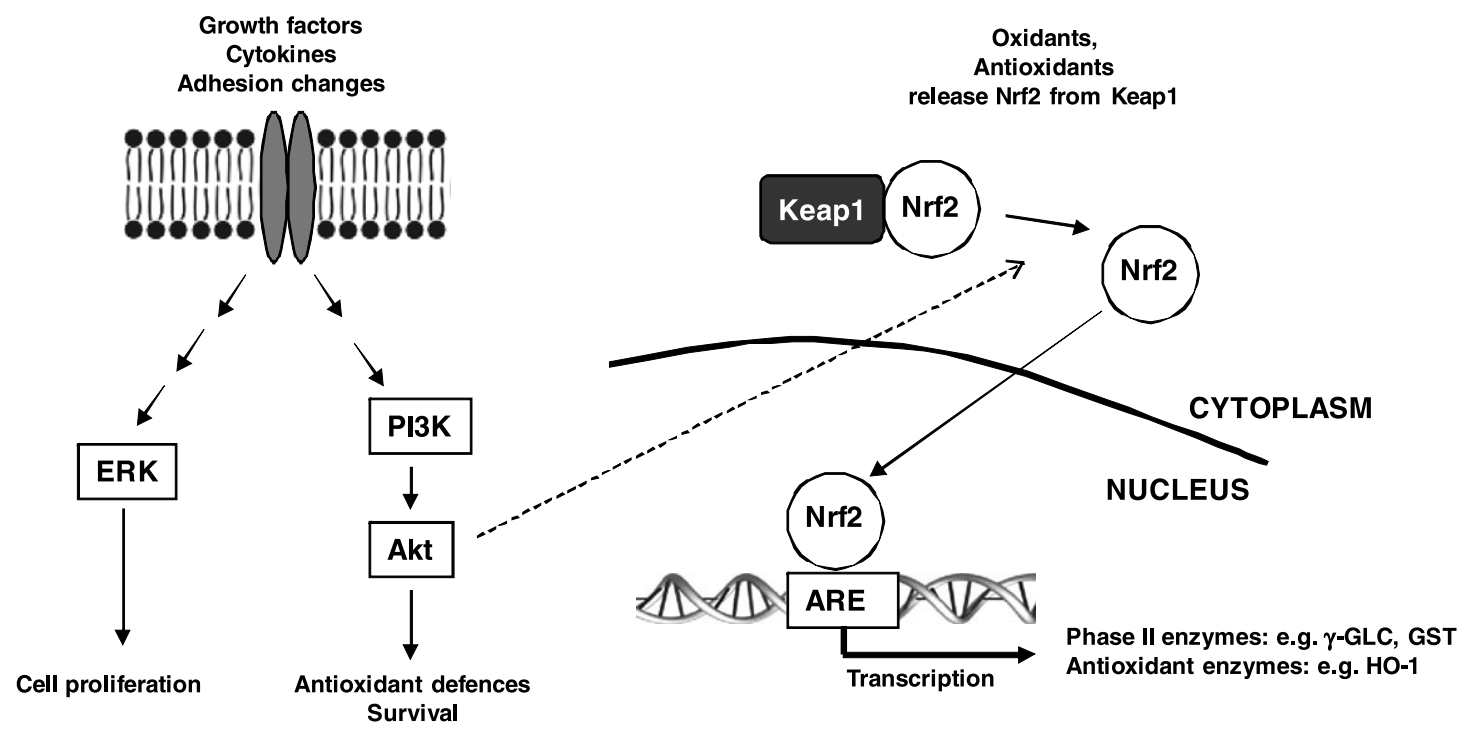

Fig. 2. Schematic representation of pathways involved in cell protection and survival: PI3K/Akt, ERK and Nfr2 pathways. Dotted line: interaction between the two pathways. 
ation induced by HT [71]. These experiments showed increased Nrf2 expression besides translocation from the cytosol into the nucleus, and heme-oxygenase induction was found to be necessary for the protective activity of HT in this model.

ARPE-19 cells represent a model of age-related macular degeneration, a process in which involves retinal pigment epithelial degeneration. HT protected these cells from acrolein-induced necrosis, decrease in total Nrf2 level, GSH loss and oxidative damage $[77,78]$. These data were confirmed using tert-butyl hydroperoxide (t-BHP) to induce apoptosis in the same cells and it was shown that Nrf2 activation by HT was necessary to maintain GSH levels, which is in turn critical for mitochondrial membrane potential stability and protection from apoptosis [79]. HT-mediated induction of Nrf2 target genes, including heme-oxygenase 1, was shown also in this experimental setting.

However, an artifactual production of biologically relevant amounts of $\mathrm{H}_{2} \mathrm{O}_{2}$ (up to $100 \mu \mathrm{M}$ ) has been demonstrated in DMEM culture media supplemented with $10-100 \mu \mathrm{M}$ concentrations of HT in the absence of pyruvate, arising from either the interaction of HT with unknown culture media constituents or its autoxidation, or both [80]. Although HT and $\mathrm{H}_{2} \mathrm{O}_{2}$ show opposite effects in most of the experiments, this finding underlines a possible confounding factor to be taken into account in in vitro experiments with HT, particularly when using high doses.

In a mice model of accelerated aging, Bayram and co-workers have shown increased expression of $\mathrm{Nfr} 2$ mRNA and Nrf2-dependent gene expression and a concomitant decrease of lipid and protein oxidation in the heart upon long-term feeding with a phenol-rich olive oil compared to animals treated with an olive oil with lower phenolic content [25]. In vitro experiments in NIH-3T3 murine fibroblasts have shown that HT, but not other phenols such as TYR, oleuropein, pinoresinol, caffeic acid, p-coumaric acid or vanillic acid, is able to induce Nrf2-dependent transactivation, and that exposure to high concentrations of HT increases Nrf2 expression [25].

\subsubsection{PI3K/Akt and ERK signaling pathways}

PI3K (phosphatidylinositol-3-kinase)/Akt and ERK (extracellular regulated protein kinase) pathways are involved in cell function maintenance and survival (Fig. 2). In HepG2 hepatic cells the treatment with HT increased phosphorylation of PI3K and ERK and not of p38MAPK or JNK [76]. The activation of these two signaling proteins was necessary to initiate Nrf2 nuclear translocation and Nrf2-dependent gene expression. Furthermore, inhibition of PI3K and ERK blocked the cytoprotective activity of HT on ROS generation induced by exposure to t-BHP [76]. In vascular endothelial cultured cells, Akt and ERK1/2 activation were involved in the protective effects of HT towards $\mathrm{H}_{2} \mathrm{O}_{2}$-induced cytotoxity [71]. Akt phosphorylation was also found in vivo in a rat model of myocardial infarction upon pre-treatment with TYR, along with increased phosphorylation of the transcription factor FOXO3a [39]. This treatment concomitantly reduced myocardial infarct size and improved left ventricular function.

Although many reports have shown that PI3/Akt pathway activation can in turn induce Nrf2 activation and regulate antioxidant functions in cells, PI3K inhibition did not prevent HT-induced Nrf2 activation in ARPE cells [79], even if the PI3K/Akt pathway was activated by HT treatment. In addition, PI3K activation was not necessary to protect t-BHP-treated ARPE cells from mitochondrial damage and apoptosis. Instead, the effects of HT on GSH and cell survival were mediated by JNK activation and JNK-mediated expression of p62, a protein related to autophagy [81]. That HT treatment might be associated with increased autophagy has also been reported in muscle of rats subjected to excessive physical exercise [59].

On the whole, these data indicate that HT can protect cells from oxidative stress through activation of survival pathways associated with growth factor receptor signaling. The role of autophagy in this context, if any, needs to be elucidated.

\subsubsection{Proteasome}

The functionality of proteasomes tends to decrease with age in tissues and in senescent cell cultures [82], leading to protein turnover derangement and accumulation of damaged proteins. Inhibition of proteasome activity can accelerate senescence [83] whereas genetic manipulations leading to proteasome overexpression are associated with prolonged survival in culture [84]. An olive leaf extract increased all three proteasomal enzymatic activities in cultured human fibroblasts, and oleuropein was identified as the phenolic compound mainly responsible for this effect [35]. Treatment with purified oleuropein prolonged the proliferative span of fibroblasts, counteracted the senescence-related decrease in proteasome activity, thereby increasing protein turnover and reducing the level of cellular 
carbonylated proteins. The authors hypothesize that these effects might be due to an oleuropein-induced conformational change in the $20 \mathrm{~S}$ proteasome $\alpha$ ring, favoring the channel open state, similarly to the action of SDS.

In in vitro tumor models, a proteasome-dependent decrease of HER-2 protein in HER-2-positive breast cancer cells has been shown upon exposure to EVOO extracts, and the two most active components were identified as acetoxypinoresinol and deacetoxyoleuropein aglycone [85]. However, in this work proteasome activity was not assayed and the increased HER-2 proteasomal degradation might have been related to other mechanisms than proteasome stimulation. Furthermore, many natural polyphenols exhibit inhibitory rather than stimulatory proteasome activity in cancer cells [86].

Although the possibility of stimulating proteasome activity with olive oil phenols is appealing in the context of aging, no further in vitro experiments have been published which shed light on this mechanism. Only one report has addressed the issue of proteasome activity upon olive oil phenol treatment in vivo, showing no difference in the hearts of SAMP8 mice treated with a phenol-rich olive oil compared to a low-phenol oil [25].

\subsection{Pathways related to energy metabolism}

The fine-tuning of energy metabolism in relation to nutrient availability is thought to be an important mechanism for maintaining cell viability and function. IGF-1 and mTOR pathways, and the regulatory enzymes AMPK and SIRT1, all involved in energy metabolism (Fig. 3), have been implicated in the aging process [87]. Substances able to modulate these mechanisms are thought to have the potential to affect health-span and, as a consequence, lifespan.

\subsection{1. $A M P K$}

AMP-activated protein kinase (AMPK) is a sensor of cellular energy status, which phosphorylates a number of targets, resulting in increases in glucose transport, fatty acid oxidation, mitochondrial biogenesis and gene transcription, and is also thought to play a role in the expression of various antioxidant enzymes. Studies in mammals indicate that AMPK controls autophagy through mTOR, stimulates pathways related to stress resistance, such as FOXO,

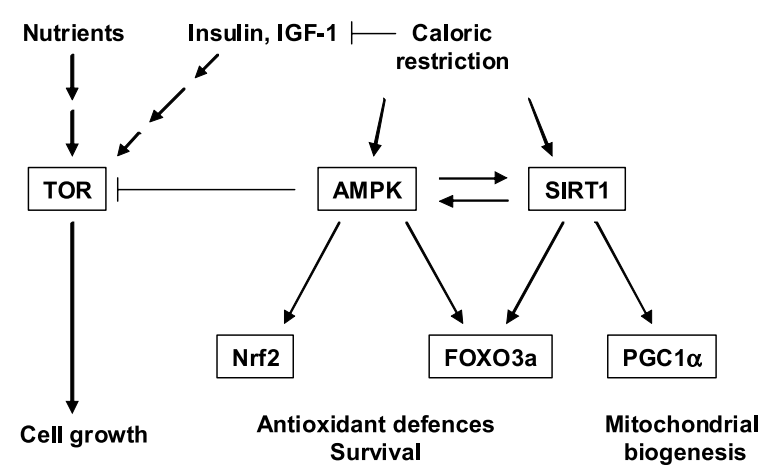

Fig. 3. Schematic representation of pathways involved in energy metabolism.

Nrf2, and SIRT1 signaling pathways, and inhibits NF$\kappa \mathrm{B}$ signaling [88]. Recent studies indicate that the responsiveness of AMPK declines with aging. Furthermore, this enzyme is activated by the treatment with anti-aging compounds such as resveratrol [89] and metformin [90].

HT at high concentrations has been shown to induce AMPK phosphorylation in ARPE-19 cells treated with acrolein [78] and in vascular endothelial cells, with subsequent FOXO3a increased expression and nuclear translocation [91]. This in turn increases catalase expression and ROS protection upon treatment of the cells with $\mathrm{H}_{2} \mathrm{O}_{2}$. A low concentration of HT was also effective in inducing a time-dependent increase in the phosphorylation of AMPK in 3T3-L1 adipocytes [92]. In a tumor cell line, HT-29, OLC inhibited cell viability, colony formation ability and COX-2 expression by activation of AMPK [93].

\subsubsection{SIRT1}

The class III histone deacetylase SIRT1 is associated with survival and longevity [94]. It activates PGC1 $\alpha$ (peroxisome proliferator-activated receptor gamma co-activator 1-alpha), a central factor in mitochondrial biogenesis, thus improving mitochondrial function [95], and modulates FOXO transcription factors [96]. The levels of SIRT1 protein have been shown to decrease with aging in brain, blood cells and plasma of C57B1/6 mice [97]. Treatment with TYR increased SIRT1 protein expression in the heart of healthy rats as well as of rats subjected to myocardial infarction [39]. Increased SIRT1 mRNA has been reported in the heart of SAMP8 mice treated with EVOO, concomitantly with increased antioxidant/detoxifying cellular defenses [25]. 


\subsubsection{Mitochondrial biogenesis and PGC1 $\alpha$}

Mitochondrial dysfunctions have been associated with aging and age-related diseases [98]. Mitochondrial biogenesis induced by resveratrol through PGC $1 \alpha$ has been associated with improved aerobic capacity and motor coordination in adult and aged mice on a high-calorie diet $[95,99]$.

Protection from mitochondrial dysfunction by HT has been reported in retinal pigment epithelial cells exposed to acrolein-induced oxidative stress [77]. In the same experimental model, HT at high concentrations induced PGC1 $\alpha$ and increased mitochondrial protein expression [78]. PGC1 $\alpha$ induction was also found in 3T3-L1 adipocytes exposed to low concentrations of HT [92]. The effects on mitochondrial DNA and on mitochondrial mass were modest and only observed at $1 \mu \mathrm{M}$, but a conspicuous increase was found in mitochondrial surface area and density. Furthermore, an increase in oxygen consumption, Complex I protein level and in the activity of Complexes I-V was shown [92]. Increased mitochondrial complex I and II activities were also shown in vivo in rats subjected to an excessive physical exercise program: the concomitant treatment with an extract enriched in HT (calculated dose $25 \mathrm{mg} / \mathrm{kg}$ ) increased animal physical endurance and prevented the decrease of PGC1 $\alpha$ in muscle [100].

All these data indicate that olive oil phenols stimulate energy metabolism pathways whose activation has been associated with anti-aging effects.

\subsection{Interaction with $\beta$-amyloid peptides and Tau protein}

Besides anti-inflammatory and antioxidant activity, both in principle beneficial in Alzheimer's disease, olive oil phenols have been shown to be capable of interacting directly with two main actors in this neuropathology, i.e. $\beta$-amyloid peptides $(\mathrm{A} \beta)$ and Tau protein. In primary hippocampal neuronal cultures low doses of OLC were able to interact with Alzheimer'sassociated $\mathrm{A} \beta$ oligomers, altering their structure and reducing their synaptotoxicity [101]. OLC has also been shown to inhibit Tau fibrillization, a process responsible for the formation of paired helical filaments through the formation of different types of chemical bonds with Tau peptides [102, 103]. Some reports have shown interactions between oleuropein and $\beta$-amyloid: oleuropein interacts in solution with the 28-amino acid residue $\mathrm{N}$-terminal fragment of the $\beta$-amyloid peptide [104] and with the $A \beta(1-40)$ peptide [105], and oleuropein aglycone disrupts $A \beta$ aggregation and reduces early $\mathrm{A} \beta$ oligomer toxicity in cell cultures [106].

A further extension of the spectrum of the beneficial properties of oleuropein in $\mathrm{AD}$ has been provided in transfected neuroblastoma cells, where oleuropein favors Amyloid Precursor Protein $\alpha$-Secretase cleavage with reduced formation of $A \beta$ oligomers [107]. Thus, olive oil phenolic compounds can alter $A \beta$ aggregation and Tau fibrillization and provide neuroprotective benefits. There is mounting interest in the search for inhibitors of the formation of protein aggregates in Alzheimer's disease, and olive oil phenols may be useful molecules for the design of future drugs to prevent neurotoxicity.

\section{Conclusions}

In vivo studies support the epidemiological evidence that olive oil has beneficial effects on the aging process, and indicate that they are partially due to the activity of phenolic compounds. The human intervention studies point to preventive effects from cardiovascular diseases, shown by the reduction of risk factors such as circulating inflammatory mediators and oxidative damage markers both in healthy volunteers and subjects at various degrees of risk. Considering that cardiovascular diseases are the leading cause of death in the human population, these effects can make an important contribution to enhanced health-span and lifespan. In addition, animal studies suggest that treatment with olive oil phenols can help prevent agerelated cognitive and motor dysfunctions, which are an important cause of disability in the elderly. In general, these data support the nutritional benefits of the dietary consumption of good-quality olive oil, and indicate the possibility of further enhancing these effects by using "functional" olive oils enriched with added phenolic fractions.

The studies on the mechanisms of action involved have been mainly conducted in vitro, and show that olive oil phenols are able to modulate many cellular functions related to survival, ability to cope with different types of stress and energy metabolism, apparently acting on intracellular signaling cascades downstream of membrane receptors. The studies performed with extracts do not allow attribution of the observed effects 
to one molecule or another, and studies with single components have used mostly HT, followed by oleuropein and OLC. As it has been repeatedly shown, olive oil phenols are rapidly and extensively metabolized, so these molecules cannot reach most tissues in significant amounts unless packaged in appropriate pharmaceutical preparations designed to deliver them to their target sites. Upon ingestion of olive oil or other phenolic complex mixtures, the molecules reaching tissues and organs are mainly derivatives of secoiridoid hydrolysis followed by further phase II metabolism, and too few data have been collected on the biological activity of these metabolites.

It can be hypothesized that this repertoire of different chemical entities deriving from the original polyphenols can act together on multiple targets rather than modifying a single molecular target. The experiments showing direct interactions with $A \beta$, Tau protein and COX indicate that the secoiridoids have the ability to modulate directly protein aggregation state and enzyme functions: whether the smaller metabolites of phenolic alcohols and acids also have this ability will have to be demonstrated. All in all, it appears that much work is still needed before the cellular and molecular mechanisms involved in the beneficial effects of olive oil phenols can be clarified. Furthermore, controlled trials with olive oil, olive derivatives or pure phenolic compounds in elderly humans might clarify whether the beneficial effects on cognitive and motor function reported in animals are attainable in humans.

In conclusion, there is growing in vivo evidence of the beneficial effects of olive oil phenols on aging but it is still confined to animal experiments. Further extensive research is needed to clarify the mechanistic explanation for these effects.

\section{Acknowledgments}

The present study was supported by the Università degli Studi di Firenze, Italy.

The Author thanks Mary Forrest for revising the manuscript.

\section{References}

[1] Perez-Lopez FR, Chedraui P, Haya J, Cuadros JL. Effects of the Mediterranean diet on longevity and age-related morbid conditions. Maturitas. 2009;64:67-79.
[2] Buckland G, Travier N, Barricarte A, Ardanaz E, MorenoIribas C, Sanchez MJ, Molina-Montes E, Chirlaque MD, Huerta JM, Navarro C, Redondo ML, Amiano P, Dorronsoro M, Larranaga N, Gonzalez CA. Olive oil intake and CHD in the European Prospective Investigation into Cancer and Nutrition Spanish cohort. Br J Nutr. 2012;1-8.

[3] Buckland G, Mayen AL, Agudo A, Travier N, Navarro C, Huerta JM, Chirlaque MD, Barricarte A, Ardanaz E, MorenoIribas C, Marin P, Quiros JR, Redondo ML, Amiano P, Dorronsoro M, Arriola L, Molina E, Sanchez MJ, Gonzalez CA. Olive oil intake and mortality within the Spanish population (EPIC-Spain). Am J Clin Nutr. 2012;96:142-9.

[4] Jimenez-Gomez Y, Lopez-Miranda J, Blanco-Colio LM, Marin C, Perez-Martinez P, Ruano J, Paniagua JA, Rodriguez F, Egido J, Perez-Jimenez F. Olive oil and walnut breakfasts reduce the postprandial inflammatory response in mononuclear cells compared with a butter breakfast in healthy men. Atherosclerosis. 2009;204:e70-6.

[5] Perez-Martinez P, Lopez-Miranda J, Blanco-Colio L, Bellido C, Jimenez Y, Moreno JA, Delgado-Lista J, Egido J, Perez-Jimenez F. The chronic intake of a Mediterranean diet enriched in virgin olive oil, decreases nuclear transcription factor kappaB activation in peripheral blood mononuclear cells from healthy men. Atherosclerosis. 2007;194:e141-6.

[6] Valls-Pedret C, Lamuela-Raventos RM, Medina-Remon A, Quintana M, Corella D, Pinto X, Martinez-Gonzalez MA, Estruch R, Ros E. Polyphenol-rich foods in the Mediterranean diet are associated with better cognitive function in elderly subjects at high cardiovascular risk. J Alzheimers Dis. 2012;29:773-82.

[7] Ghanbari R, Anwar F, Alkharfy KM, Gilani AH, Saari N. Valuable Nutrients and Functional Bioactives in Different Parts of Olive (Olea europaea L.)-A Review. Int J Mol Sci. 2012;13:3291-340.

[8] Owen RW, Giacosa A, Hull WE, Haubner R, Spiegelhalder B, Bartsch H. The antioxidant/anticancer potential of phenolic compounds isolated from olive oil. Eur J Cancer. 2000;36:1235-47.

[9] Obied HK, Allen MS, Bedgood DR, Prenzler PD, Robards $\mathrm{K}$, Stockmann R. Bioactivity and analysis of biophenols recovered from olive mill waste. J Agric Food Chem. 2005;53:823-37.

[10] Ramirez-Tortosa MC, Urbano G, Lopez-Jurado M, Nestares T, Gomez MC, Mir A, Ros E, Mataix J, Gil A. Extra-virgin olive oil increases the resistance of LDL to oxidation more than refined olive oil in free-living men with peripheral vascular disease. J Nutr. 1999;129:2177-83.

[11] Vissers MN, Zock PL, Wiseman SA, Meyboom S, Katan MB. Effect of phenol-rich extra virgin olive oil on markers of oxidation in healthy volunteers. Eur J Clin Nutr. 2001;55:33441.

[12] Visioli F, Caruso D, Galli C, Viappiani S, Galli G, Sala A. Olive oils rich in natural catecholic phenols decrease isoprostane excretion in humans. Biochem Biophys Res Commun. 2000;278:797-9.

[13] Vissers MN, Zock PL, Leenen R, Roodenburg AJ, van Putte KP, Katan MB. Effect of consumption of phenols from olives and extra virgin olive oil on LDL oxidizability in healthy humans. Free Radic Res. 2001;35:619-29. 
[14] Covas MI. Bioactive effects of olive oil phenolic compounds in humans: Reduction of heart disease factors and oxidative damage. Inflammopharmacology. 2008;16:216-8.

[15] Raederstorff D. Antioxidant activity of olive polyphenols in humans: A review. Int J Vitam Nutr Res. 2009;79:152-65.

[16] Cicerale S, Lucas LJ, Keast RS. Antimicrobial, antioxidant and anti-inflammatory phenolic activities in extra virgin olive oil. Curr Opin Biotechnol. 2012;23:129-35.

[17] Visioli F. Olive oil phenolics: Where do we stand? Where should we go? J Sci Food Agric. 2012;92:2017-9.

[18] European Food Safety Authority. EFSA Journal. 2011;9: 2033.

[19] Lopez-Miranda J, Perez-Jimenez F, Ros E, De Caterina R, Badimon L, Covas MI, Escrich E, Ordovas JM, Soriguer F, Abia R, de la Lastra CA, Battino M, Corella D, ChamorroQuiros J, Delgado-Lista J, Giugliano D, Esposito K, Estruch R, Fernandez-Real JM, Gaforio JJ, La Vecchia C, Lairon D, Lopez-Segura F, Mata P, Menendez JA, Muriana FJ, Osada J, Panagiotakos DB, Paniagua JA, Perez-Martinez P, Perona J, Peinado MA, Pineda-Priego M, Poulsen HE, Quiles JL, Ramirez-Tortosa MC, Ruano J, Serra-Majem L, Sola R, Solanas M, Solfrizzi V, Torre-Fornell R, Trichopoulou A, Uceda M, Villalba-Montoro JM, Villar-Ortiz JR, Visioli F, Yiannakouris N. Olive oil and health: Summary of the II international conference on olive oil and health consensus report, Jaen and Cordoba (Spain) 2008. Nutr Metab Cardiovasc Dis. 2010;20:284-94.

[20] Castaner O, Covas MI, Khymenets O, Nyyssonen K, Konstantinidou V, Zunft HF, de la TR, Munoz-Aguayo D, Vila J, Fito M. Protection of LDL from oxidation by olive oil polyphenols is associated with a downregulation of CD40ligand expression and its downstream products in vivo in humans. Am J Clin Nutr. 2012;95:1238-44.

[21] Moreno-Luna R, Munoz-Hernandez R, Miranda ML, Costa AF, Jimenez-Jimenez L, Vallejo-Vaz AJ, Muriana FJ, Villar J, Stiefel P. Olive Oil Polyphenols Decrease Blood Pressure and Improve Endothelial Function in Young Women with Mild Hypertension. Am J Hypertens. 2012;25(12):1299304.

[22] Jacomelli M, Pitozzi V, Zaid M, Larrosa M, Tonini G, Martini A, Urbani S, Taticchi A, Servili M, Dolara P, Giovannelli L. Dietary extra-virgin olive oil rich in phenolic antioxidants and the aging process: Long-term effects in the rat. $\mathrm{J}$ Nutr Biochem. 2010;21:290-6.

[23] Pitozzi V, Jacomelli M, Zaid M, Luceri C, Bigagli E, Lodovici M, Ghelardini C, Vivoli E, Norcini M, Gianfriddo M, Esposto S, Servili M, Morozzi G, Baldi E, Bucherelli C, Dolara P, Giovannelli L. Effects of dietary extra-virgin olive oil on behaviour and brain biochemical parameters in ageing rats. Br J Nutr. 2010;103:1674-83.

[24] Pitozzi V, Jacomelli M, Catelan D, Servili M, Taticchi A, Biggeri A, Dolara P, Giovannelli L. Long-term dietary extravirgin olive oil rich in polyphenols reverses age-related dysfunctions in motor coordination and contextual memory in mice: Role of oxidative stress. Rejuvenation Res. 2012;15(6):601-12.

[25] Bayram B, Ozcelik B, Grimm S, Roeder T, Schrader C, Ernst IM, Wagner AE, Grune T, Frank J, Rimbach G. A diet rich in olive oil phenolics reduces oxidative stress in the heart of
SAMP8 mice by induction of Nrf2-dependent gene expression. Rejuvenation Res. 2012;15:71-81.

[26] Farr SA, Price TO, Dominguez LJ, Motisi A, Saiano F, Niehoff ML, Morley JE, Banks WA, Ercal N, Barbagallo M. Extra Virgin Olive Oil Improves Learning and Memory in SAMP8 Mice. J Alzheimers Dis. 2011;28(1):81-92.

[27] Wu YT, Lin LC, Tsai TH. Measurement of free hydroxytyrosol in microdialysates from blood and brain of anesthetized rats by liquid chromatography with fluorescence detection. $\mathbf{J}$ Chromatogr A. 2009;1216:3501-7.

[28] Serra A, Rubio L, Borras X, Macia A, Romero MP, Motilva MJ. Distribution of olive oil phenolic compounds in rat tissues after administration of a phenolic extract from olive cake. Mol Nutr Food Res. 2011;56(3):486-96.

[29] De La Cruz JP, Del Rio S, Arrebola MM, Lopez-Villodres JA, Jebrouni N, Gonzalez-Correa JA. Effect of virgin olive oil plus acetylsalicylic acid on brain slices damage after hypoxia-reoxygenation in rats with type 1-like diabetes mellitus. Neurosci Lett. 2010;471:89-93.

[30] Gonzalez-Correa JA, Munoz-Marin J, Arrebola MM, Guerrero A, Narbona F, Lopez-Villodres JA, De La Cruz JP. Dietary virgin olive oil reduces oxidative stress and cellular damage in rat brain slices subjected to hypoxiareoxygenation. Lipids. 2007;42:921-9.

[31] Puel C, Quintin A, Agalias A, Mathey J, Obled C, Mazur A, Davicco MJ, Lebecque P, Skaltsounis AL, Coxam V. Olive oil and its main phenolic micronutrient (oleuropein) prevent inflammation-induced bone loss in the ovariectomised rat. $\mathrm{Br}$ J Nutr. 2004;92:119-27.

[32] Puel C, Mardon J, Agalias A, Davicco MJ, Lebecque P, Mazur A, Horcajada MN, Skaltsounis AL, Coxam V. Major phenolic compounds in olive oil modulate bone loss in an ovariectomy/inflammation experimental model. J Agric Food Chem. 2008;56:9417-22.

[33] Santiago-Mora R, Casado-Diaz A, De Castro MD, QuesadaGomez JM. Oleuropein enhances osteoblastogenesis and inhibits adipogenesis: The effect on differentiation in stem cells derived from bone marrow. Osteoporos Int. 2011;22:675-84.

[34] Sarsour EH, Kumar MG, Kalen AL, Goswami M, Buettner GR, Goswami PC. MnSOD activity regulates hydroxytyrosol-induced extension of chronological lifespan. Age (Dordr.). 2012;34:95-109.

[35] Katsiki M, Chondrogianni N, Chinou I, Rivett AJ, Gonos ES. The olive constituent oleuropein exhibits proteasome stimulatory properties in vitro and confers life span extension of human embryonic fibroblasts. Rejuvenation Res. 2007; 10:157-72.

[36] Vazquez-Martin A, Fernandez-Arroyo S, Cufi S, OliverasFerraros C, Lozano-Sanchez J, Vellon L, Micol V, Joven J, Segura-Carretero A, Menendez JA. Phenolic secoiridoids in extra virgin olive oil impede fibrogenic and oncogenic epithelial-to-mesenchymal transition: Extra virgin olive oil as a source of novel antiaging phytochemicals. Rejuvenation Res. 2012;15:3-21.

[37] Aguilera A, Aroeira LS, Ramirez-Huesca M, Perez-Lozano ML, Cirugeda A, Bajo MA, del Peso G, ValenzuelaFernandez A, Sanchez-Tomero JA, Lopez-Cabrera M, Selgas R. Effects of rapamycin on the epithelial-to-mesenchymal 
transition of human peritoneal mesothelial cells. Int J Artif Organs. 2005;28:164-9.

[38] Cufi S, Vazquez-Martin A, Oliveras-Ferraros C, MartinCastillo B, Joven J, Menendez JA. Metformin against TGFbeta-induced epithelial-to-mesenchymal transition (EMT): From cancer stem cells to aging-associated fibrosis. Cell Cycle. 2010;9:4461-8.

[39] Samuel SM, Thirunavukkarasu M, Penumathsa SV, Paul D, Maulik N. Akt/FOXO3a/SIRT1-mediated cardioprotection by $\mathrm{n}$-tyrosol against ischemic stress in rat in vivo model of myocardial infarction: Switching gears toward survival and longevity. J Agric Food Chem. 2008;56:9692-8.

[40] Tuck KL, Hayball PJ. Major phenolic compounds in olive oil: Metabolism and health effects. J Nutr Biochem. 2002;13:63644.

[41] Suarez M, Valls RM, Romero MP, Macia A, Fernandez S, Giralt M, Sola R, Motilva MJ. Bioavailability of phenols from a phenol-enriched olive oil. Br J Nutr. 2011;106:1691-701.

[42] Edgecombe SC, Stretch GL, Hayball PJ. Oleuropein, an antioxidant polyphenol from olive oil, is poorly absorbed from isolated perfused rat intestine. J Nutr. 2000;130:29963002.

[43] Corona G, Tzounis X, Assunta DM, Deiana M, Debnam ES, Visioli F, Spencer JP. The fate of olive oil polyphenols in the gastrointestinal tract: Implications of gastric and colonic microflora-dependent biotransformation. Free Radic Res. 2006;40:647-58.

[44] Pinto J, Paiva-Martins F, Corona G, Debnam ES, Jose OrunaConcha M, Vauzour D, Gordon MH, Spencer JP. Absorption and metabolism of olive oil secoiridoids in the small intestine. Br J Nutr. 2011;105:1607-18.

[45] Vissers MN, Zock PL, Katan MB. Bioavailability and antioxidant effects of olive oil phenols in humans: A review. Eur J Clin Nutr. 2004;58:955-65.

[46] Visioli F, Galli C, Bornet F, Mattei A, Patelli R, Galli G, Caruso D. Olive oil phenolics are dose-dependently absorbed in humans. FEBS Lett. 2000;468:159-60.

[47] Caruso D, Visioli F, Patelli R, Galli C, Galli G. Urinary excretion of olive oil phenols and their metabolites in humans. Metabolism. 2001;50:1426-8.

[48] Khymenets O, Fito M, Tourino S, Munoz-Aguayo D, Pujadas M, Torres JL, Joglar J, Farre M, Covas MI, de la TR. Antioxidant activities of hydroxytyrosol main metabolites do not contribute to beneficial health effects after olive oil ingestion. Drug Metab Dispos. 2010;38:1417-21.

[49] Tuck KL, Hayball PJ, Stupans I. Structural characterization of the metabolites of hydroxytyrosol, the principal phenolic component in olive oil, in rats. J Agric Food Chem. 2002;50:2404-9.

[50] Jenny NS. Inflammation in aging: Cause, effect, or both? Discov Med. 2012;13:451-60.

[51] Ownby RL. Neuroinflammation and cognitive aging. Curr Psychiatry Rep. 2010;12:39-45.

[52] Salminen A, Kauppinen A, Kaarniranta K. Emerging role of NF-kappaB signaling in the induction of senescenceassociated secretory phenotype (SASP). Cell Signal. 2012;24:835-45.

[53] Lee MY, Wang Y, Vanhoutte PM. Senescence of cultured porcine coronary arterial endothelial cells is associated with accelerated oxidative stress and activation of NFkB. J Vasc Res. 2010;47:287-98.

[54] Tilstra JS, Robinson AR, Wang J, Gregg SQ, Clauson CL, Reay DP, Nasto LA, St Croix CM, Usas A, Vo N, Huard J, Clemens PR, Stolz DB, Guttridge DC, Watkins SC, Garinis GA, Wang Y, Niedernhofer LJ, Robbins PD. NF-kappaB inhibition delays DNA damage-induced senescence and aging in mice. J Clin Invest. 2012;122:2601-12.

[55] Goyarzu P, Malin DH, Lau FC, Taglialatela G, Moon WD, Jennings R, Moy E, Moy D, Lippold S, Shukitt-Hale B, Joseph JA. Blueberry supplemented diet: Effects on object recognition memory and nuclear factor-kappa B levels in aged rats. Nutr Neurosci. 2004;7:75-83.

[56] Laurent-Thibault C, Arseneault M, Longpre F, Ramassamy C. Tyrosol and hydroxytyrosol, two main components of olive oil, protect N2a cells against amyloid-beta-induced toxicity. Involvement of the NF-kappaB signaling. Curr Alzheimer Res. 2011;8:543-51.

[57] Sangiovanni E, Colombo E, Fumagalli M, Abbiati F, Caruso D, Dell'agli M. Inhibition of NF- kappaB Activity by Minor Polar Components of Extra-Virgin Olive Oil at Gastric Level. Phytother Res. 2012;26:1569-71.

[58] Carluccio MA, Siculella L, Ancora MA, Massaro M, Scoditti E, Storelli C, Visioli F, Distante A, De Caterina $\mathrm{R}$. Olive oil and red wine antioxidant polyphenols inhibit endothelial activation: Antiatherogenic properties of Mediterranean diet phytochemicals. Arterioscler Thromb Vasc Biol. 2003;23:622-9.

[59] Carluccio MA, Ancora MA, Massaro M, Carluccio M, Scoditti E, Distante A, Storelli C, De Caterina R. Homocysteine induces VCAM-1 gene expression through NF-kappaB and $\mathrm{NAD}(\mathrm{P}) \mathrm{H}$ oxidase activation: Protective role of Mediterranean diet polyphenolic antioxidants. Am J Physiol Heart Circ Physiol. 2007;293:H2344-54.

[60] Palmieri D, Aliakbarian B, Casazza AA, Ferrari N, Spinella G, Pane B, Cafueri G, Perego P, Palombo D. Effects of polyphenol extract from olive pomace on anoxia-induced endothelial dysfunction. Microvasc Res. 2012;83:281-9.

[61] Dell'agli M, Fagnani R, Galli GV, Maschi O, Gilardi F, Bellosta S, Crestani M, Bosisio E, De Fabiani E, Caruso D. Olive oil phenols modulate the expression of metalloproteinase 9 in THP-1 cells by acting on nuclear factor-kappaB signaling. J Agric Food Chem. 2010;58:2246-52.

[62] Brunelleschi S, Bardelli C, Amoruso A, Gunella G, Ieri F, Romani A, Malorni W, Franconi F. Minor polar compounds extra-virgin olive oil extract (MPC-OOE) inhibits NF-kappa B translocation in human monocyte/macrophages. Pharmacol Res. 2007;56:542-9.

[63] Wang L, Geng C, Jiang L, Gong D, Liu D, Yoshimura $\mathrm{H}$, Zhong L. The anti-atherosclerotic effect of olive leaf extract is related to suppressed inflammatory response in rabbits with experimental atherosclerosis. Eur J Nutr. 2008;47:235-43.

[64] Beauchamp GK, Keast RS, Morel D, Lin J, Pika J, Han Q, Lee $\mathrm{CH}$, Smith AB, Breslin PA. Phytochemistry: Ibuprofen-like activity in extra-virgin olive oil. Nature. 2005;437:45-6.

[65] Procopio A, Alcaro S, Nardi M, Oliverio M, Ortuso F, Sacchetta P, Pieragostino D, Sindona G. Synthesis, biological evaluation, and molecular modeling of oleuropein and its 
semisynthetic derivatives as cyclooxygenase inhibitors. J Agric Food Chem. 2009;57:11161-7.

[66] Cuenda A, Rousseau S. p38 MAP-kinases pathway regulation, function and role in human diseases. Biochim Biophys Acta. 2007;1773:1358-75.

[67] Freund A, Patil CK, Campisi J. p38MAPK is a novel DNA damage response-independent regulator of the senescenceassociated secretory phenotype. EMBO J. 2011;30:1536-48.

[68] Sanchez-Fidalgo S, Sanchez d, I, Cardeno A, Alarcon dlL. Influence of extra virgin olive oil diet enriched with hydroxytyrosol in a chronic DSS colitis model. Eur J Nutr. 2012;51:497-506.

[69] Corona G, Deiana M, Incani A, Vauzour D, Dessi MA, Spencer JP. Inhibition of p38/CREB phosphorylation and COX-2 expression by olive oil polyphenols underlies their anti-proliferative effects. Biochem. Biophys Res Commun. 2007;362:606-11.

[70] Oliveras-Ferraros C, Fernandez-Arroyo S, Vazquez-Martin A, Lozano-Sanchez J, Cufi S, Joven J, Micol V, FernandezGutierrez A, Segura-Carretero A, Menendez JA. Crude phenolic extracts from extra virgin olive oil circumvent $d e$ novo breast cancer resistance to HER1/HER2-targeting drugs by inducing GADD45-sensed cellular stress, G2/M arrest and hyperacetylation of Histone H3. Int J Oncol. 2011;38:153347.

[71] Zrelli H, Matsuoka M, Kitazaki S, Araki M, Kusunoki M, Zarrouk M, Miyazaki H. Hydroxytyrosol induces proliferation and cytoprotection against oxidative injury in vascular endothelial cells: Role of Nrf2 activation and HO-1 induction. J Agric Food Chem. 2011;59:4473-82.

[72] Martinez-Gonzalez J, Rodriguez-Rodriguez R, GonzalezDiez M, Rodriguez C, Herrera MD, Ruiz-Gutierrez V, Badimon L. Oleanolic acid induces prostacyclin release in human vascular smooth muscle cells through a cyclooxygenase-2dependent mechanism. J Nutr. 2008;138:443-8.

[73] Scialo F, Mallikarjun V, Stefanatos R, Sanz A. Regulation of Lifespan by the Mitochondrial Electron Transport Chain: Reactive Oxygen Species-Dependent and Reactive Oxygen Species-Independent Mechanisms. Antioxid Redox Signal. 2012.

[74] Hollman PC, Cassidy A, Comte B, Heinonen M, Richelle M, Richling E, Serafini M, Scalbert A, Sies H, Vidry S. The biological relevance of direct antioxidant effects of polyphenols for cardiovascular health in humans is not established. J Nutr. 2011;141:989S-1009S.

[75] Scapagnini G, Vasto S, Abraham NG, Caruso C, Zella D, Fabio G. Modulation of Nrf2/ARE pathway by food polyphenols: A nutritional neuroprotective strategy for cognitive and neurodegenerative disorders. Mol Neurobiol. 2011;44:192201.

[76] Martin MA, Ramos S, Granado-Serrano AB, RodriguezRamiro I, Trujillo M, Bravo L, Goya L. Hydroxytyrosol induces antioxidant/detoxificant enzymes and Nrf2 translocation via extracellular regulated kinases and phosphatidylinositol-3-kinase/protein kinase B pathways in HepG2 cells. Mol Nutr Food Res. 2010;54:956-66.

[77] Liu Z, Sun L, Zhu L, Jia X, Li X, Jia H, Wang Y, Weber P, Long J, Liu J. Hydroxytyrosol protects retinal pigment epithelial cells from acrolein-induced oxidative stress and mitochondrial dysfunction. J Neurochem. 2007;103:2690700.

[78] Zhu L, Liu Z, Feng Z, Hao J, Shen W, Li X, Sun L, Sharman E, Wang Y, Wertz K, Weber P, Shi X, Liu J. Hydroxytyrosol protects against oxidative damage by simultaneous activation of mitochondrial biogenesis and phase II detoxifying enzyme systems in retinal pigment epithelial cells. J Nutr Biochem. 2010;21:1089-98.

[79] Zou X, Feng Z, Li Y, Wang Y, Wertz K, Weber P, Fu Y, Liu J. Stimulation of GSH synthesis to prevent oxidative stress-induced apoptosis by hydroxytyrosol in human retinal pigment epithelial cells: Activation of $\mathrm{Nrf} 2$ and JNK-p62/SQSTM1 pathways. J Nutr Biochem. 2012;23:9941006.

[80] Schaffer S, Halliwell B. Comment on hydroxytyrosol induces proliferation and cytoprotection against oxidative injury in vascular endothelial cells: Role of Nrf2 activation and HO-1 induction. J Agric Food Chem. 2011;59:10770-1.

[81] Fan W, Tang Z, Chen D, Moughon D, Ding X, Chen S, Zhu M, Zhong Q. Keap1 facilitates p62-mediated ubiquitin aggregate clearance via autophagy. Autophagy. 2010;6:614-21.

[82] Chondrogianni N, Gonos ES. Proteasome dysfunction in mammalian aging: Steps and factors involved. Exp Gerontol. 2005;40:931-8

[83] Chondrogianni N, Gonos ES. Proteasome inhibition induces a senescence-like phenotype in primary human fibroblasts cultures. Biogerontology. 2004;5:55-61.

[84] Chondrogianni N, Tzavelas C, Pemberton AJ, Nezis IP, Rivett AJ, Gonos ES. Overexpression of proteasome beta5 assembled subunit increases the amount of proteasome and confers ameliorated response to oxidative stress and higher survival rates. J Biol Chem. 2005;280:11840-50.

[85] Menendez JA, Vazquez-Martin A, Garcia-Villalba R, Carrasco-Pancorbo A, Oliveras-Ferraros C, FernandezGutierrez A, Segura-Carretero A. tabAnti-HER2 (erbB-2) oncogene effects of phenolic compounds directly isolated from commercial Extra-Virgin Olive Oil (EVOO). BMC Cancer. 2008;8:377.

[86] Shen M, Chan TH, Dou QP. Targeting tumor ubiquitinproteasome pathway with polyphenols for chemosensitization. Anticancer Agents Med Chem. 2012;12:891901.

[87] Fontana L, Partridge L, Longo VD. Extending healthy life span-from yeast to humans. Science. 2010;328:321-6.

[88] Salminen A, Kaarniranta K. AMP-activated protein kinase (AMPK) controls the aging process via an integrated signaling network. Ageing Res Rev. 2012;11:230-41.

[89] Hwang JT, Kwon DY, Park OJ, Kim MS. Resveratrol protects ROS-induced cell death by activating AMPK in H9c2 cardiac muscle cells. Genes Nutr. 2008;2:323-6.

[90] Zou MH, Kirkpatrick SS, Davis BJ, Nelson JS, Wiles WG, Schlattner U, Neumann D, Brownlee M, Freeman MB, Goldman MH. Activation of the AMP-activated protein kinase by the anti-diabetic drug metformin in vivo. Role of mitochondrial reactive nitrogen species. J Biol Chem. 2004;279:43940-51.

[91] Zrelli H, Matsuoka M, Kitazaki S, Zarrouk M, Miyazaki H. Hydroxytyrosol reduces intracellular reactive oxygen species levels in vascular endothelial cells by upregulating catalase 
expression through the AMPK-FOXO3a pathway. Eur J Pharmacol. 2011;660:275-82.

[92] Hao J, Shen W, Yu G, Jia H, Li X, Feng Z, Wang Y, Weber P, Wertz K, Sharman E, Liu J. Hydroxytyrosol promotes mitochondrial biogenesis and mitochondrial function in 3T3-L1 adipocytes. J Nutr Biochem. 2010;21:634-44.

[93] Khanal P, Oh WK, Yun HJ, Namgoong GM, Ahn SG, Kwon SM, Choi HK, Choi HS. p-HPEA-EDA, a phenolic compound of virgin olive oil, activates AMP-activated protein kinase to inhibit carcinogenesis. Carcinogenesis. 2011;32:545-53.

[94] Houtkooper RH, Pirinen E, Auwerx J. Sirtuins as regulators of metabolism and healthspan. Nat Rev Mol Cell Biol. 2012;13:225-38.

[95] Lagouge M, Argmann C, Gerhart-Hines Z, Meziane H, Lerin C, Daussin F, Messadeq N, Milne J, Lambert P, Elliott P, Geny B, Laakso M, Puigserver P, Auwerx J. Resveratrol improves mitochondrial function and protects against metabolic disease by activating SIRT1 and PGC-1alpha. Cell. 2006; 127:1109-22.

[96] Brunet A, Sweeney LB, Sturgill JF, Chua KF, Greer PL, Lin Y, Tran H, Ross SE, Mostoslavsky R, Cohen HY, Hu LS, Cheng HL, Jedrychowski MP, Gygi SP, Sinclair DA, Alt FW, Greenberg ME. Stress-dependent regulation of FOXO transcription factors by the SIRT1 deacetylase. Science. 2004;303:2011-5.

[97] Li X, Khanna A, Li N, Wang E. Circulatory miR34a as an RNAbased, noninvasive biomarker for brain aging. Aging (Albany. NY). 2011;3:985-1002.

[98] Reddy PH, Reddy TP. Mitochondria as a therapeutic target for aging and neurodegenerative diseases. Curr Alzheimer Res. 2011;8:393-409.

[99] Baur JA, Pearson KJ, Price NL, Jamieson HA, Lerin C, Kalra A, Prabhu VV, Allard JS, Lopez-Lluch G, Lewis K, Pistell PJ, Poosala S, Becker KG, Boss O, Gwinn D, Wang MY, Ramaswamy S, Fishbein KW, Spencer RG, Lakatta EG, Le Couteur D, Shaw RJ, Navas P, Puigserver P, Ingram DK, de Cabo R, Sinclair DA. Resveratrol improves health and survival of mice on a high-calorie diet. Nature. 2006;444:337-42.
[100] Feng Z, Bai L, Yan J, Li Y, Shen W, Wang Y, Wertz K, Weber P, Zhang Y, Chen Y, Liu J. Mitochondrial dynamic remodeling in strenuous exercise-induced muscle and mitochondrial dysfunction: Regulatory effects of hydroxytyrosol. Free Radic Biol Med. 2011;50:1437-46.

[101] Pitt J, Roth W, Lacor P, Smith AB, III, Blankenship M, Velasco P, De Felice F, Breslin P, Klein WL. Alzheimer's-associated Abeta oligomers show altered structure, immunoreactivity and synaptotoxicity with low doses of oleocanthal. Toxicol Appl Pharmacol. 2009;240:189-97.

[102] Li W, Sperry JB, Crowe A, Trojanowski JQ, Smith AB, III, Lee VM. Inhibition of tau fibrillization by oleocanthal via reaction with the amino groups of tau. J Neurochem. 2009;110:1339-51.

[103] Monti MC, Margarucci L, Tosco A, Riccio R, Casapullo A. New insights on the interaction mechanism between tau protein and oleocanthal, an extra-virgin olive-oil bioactive component. Food Funct. 2011;2:423-8.

[104] Benaki D, Stathopoulou K, Leondiadis L, Ferderigos N, Pelecanou M, Mikros E. Detection of interactions of the betaamyloid peptide with small molecules employing transferred NOEs. J Pept Sci. 2009;15:435-41.

[105] Galanakis PA, Bazoti FN, Bergquist J, Markides K, Spyroulias GA, Tsarbopoulos A. Study of the interaction between the amyloid beta peptide (1-40) and antioxidant compounds by nuclear magnetic resonance spectroscopy. Biopolymers. 2011;96:316-27.

[106] Rigacci S, Guidotti V, Bucciantini M, Nichino D, Relini A, Berti A, Stefani M. Abeta(1-42) aggregates into non-toxic amyloid assemblies in the presence of the natural polyphenol oleuropein aglycon. Curr Alzheimer Res. 2011;8:841-52.

[107] Kostomoiri M, Fragkouli A, Sagnou M, Skaltsounis LA, Pelecanou M, Tsilibary EC, Tauzinia AK. Oleuropein, an Anti-oxidant Polyphenol Constituent of Olive Promotes alpha-Secretase Cleavage of the Amyloid Precursor Protein (AbetaPP). Cell Mol Neurobiol. 2012;33(1):147-54. 